This report was prepared as an acoount of work sponsored by an agency of the United Sistes Government. Neither the United Siutes Government nor eny atency thereof, nor sny of theit eny warranty. e.press or implied, or essumes any legal liability or tesponsicompletente, or usefulness of any inlormation, apparatus, product, of bility for the eccuracy, completenes, or usc would not infringe pivately owned tights. Reictprocess disclowed, of represents that its we woul, process, or service by teade name- tradematk. ence herein to any specific commersial produtily constitute or imply its endorsement, recsm. manufacturer, or atherwise does nod nectate Goresnment of any anency thereof. The views mendation, or lavoring by the United States Goretnment of any ate or reflect thoue of the and opinions of euthors expresed herein do not

Uniled Siates Government of any a gency thereof.

UCLA/PPG--1084

DE88 000822

\title{
ALT-I Pump Limiter Experiments
}

D.M. Goebel, R.W. Conn, G.A. Campbell, W.K. Leung

K.H. Dippel ${ }^{1}$, K.H. Finken', G.H. Wolf ${ }^{l}$

G.J. Thomas' ${ }^{2}$ A.E. Pontau2 2 W. Hsu ${ }^{2}$

UCLA-PPG-1084 Seplember, 1987

\section{Department of Mechanical, Aerospace and Nuclear Enginecring Institute of Plasma and Fusion Research University of California, Los Angcles, CA, 90024, U.S.A.}

${ }^{1}$ Institute of Plasma Physics, Association Euratom-KFA Juelich, F.R.G.

${ }^{2}$ Sandia National Laboratories, Livermore, California, 94550, U.S.A. 


\title{
ALT-I Pump Limiter Experiments
}

\author{
D.M. Goebel, R.W. Conn, G.A. Campbell, W.K. Leung \\ University of California, Los Angeles, Los Angeles, CA 90024 , U.S.A. \\ K.H. Dippel, K.H. Finken, G.H. Wolf \\ Institute of Plasma Physics, Association Euratom-KFA Juelich, F.R.G. \\ G.J. Thomas, A.E. Pontau, W. Hsu \\ Sandia National Laboratories, Livermore, CA 94550, U.S.A.
}

\begin{abstract}
Results from the ALT-I pump limiter experiments in TEXTOR are presented. ALT-I has demonstrated control of the plasma density in a high recycling tokamak by pumping up to $15 \%$ of the core efflux. The closed pump limiter designs with restricted entrance geo:netries to reduce the backflow of neutral gas to the plasma remove over $50 \%$ of the ion flux incident on the collection slot. Up to $80 \%$ of the entrance ion flux is removed when the edge electron temperature is less than $10 \mathrm{eV}$ and plasma-neutral gas interactions are minimized inside the limiter. Results from a 3-D Monte Carlo neutral gas transport code agree closely with these experimental results. The compound curvature of the head is found to distribute the heat over the surface as predicted in the original designs. Impurity removal experiments demonstrate that significant helium exhaust can be achieved with a pump limiter. During ohmic heating in TEXTOR, the energy and particle confinement times are proportional to the line averaged core density. With ICRH auxiliary heating, $\tau_{E}$ follows $L$-mode scaling independent of particle removal by the pump limiter. Pump limiter operation does not directly modify the SOL plasma density and electron temperature, but controls the core plasma density by changing the global recycling at the boundary. The global particle confinement, the particle flux to the limiter, and the edge electron temperature follow the changes in the core density ard auxiliary heating power.
\end{abstract}




\section{INTRODUCTION}

Pump limiters have demonstrated significant power removal and particle exhaust in present generation tokamaks, and represent a viable option for providing control of the plasma density and power distribution in large machines. The additional requirements of impurity removal and helium ash exhaust have also been demonstrated to some extent by pump limiters. The concepts of pump limiter design for particle removal and power handling, and recent experimental results, have been reviewed in detail elsewhere. $1-3$

Experiments to investigate particle and power removal by pump limiters have been made on several tokamaks. The Advanced Limiter Test (ALT-I) ${ }^{4-7}$ is a series of pump limiter experiments on the TEXTOR tokamak. 8 The purpose of these experiments ${ }^{9}$ is to study the particle removal capabilities of several actively-pumped limiter modules of different geometries in the long pulse-length plasma of TEXTOR. The ALT experiments have several features not avatlable in the other pump limiter studies. The modules have been designed to demonstrate the dependence of the particle removal efficiency on the plasma collection geometry. A comprehensive set of edge diagnostics is used to monitor the edge plasma parameters, and to study their effect on the pumping efficiency. Plasma density control is studied in the regime of high neutral recycling from the hot liner and walls. TEXTOR has a pulse length of over 3 seconds, which is long compared to the gas flow time constants in the tokamak vessel. Therefore, particle removal on time scales longer than the particle containment time in the vessel, $\tau_{p}$ *, can be studied. Impurity removal rates by the different pump limiter geometries, and the removal efficiency during active pumping, have been investigated. Observation of the full limiter surface by IR cameras during ohmic and ICRH phases provides information on the power removal capabilities of pump limiters. Sudies of pump limiter performance and the SOL plasma modifications during ICRH auxiliary heating ${ }^{10}$ of up to $2 \mathrm{MW}$ have also been made.

The TEXTOR tokamak ${ }^{8}$ has been described elsewhere. Typical conditions during ALT experiments are: $R_{o}=1.75 \mathrm{~m}, \mathrm{a}=40-48 \mathrm{~cm}, \mathrm{I}_{\mathrm{p}}=350-480 \mathrm{kA}, \mathrm{B}_{\mathrm{T}}=2.0 \mathrm{~T}, \mathrm{n}_{\mathrm{e}}=1-5 \times 10^{13} \mathrm{~cm}^{-3}$, $\mathrm{T}_{\mathrm{e}}(0)<1.5 \mathrm{keV}$, and $\mathrm{T}_{\mathrm{i}} \leq 1 \mathrm{keV}$. Auxiliary heating by ICRH of up to $2.4 \mathrm{MW}$ for 3 seconds is 
available. The liner temperature is normally maintained between $150-300^{\circ} \mathrm{C}$, and the walls are carbonized $^{11}$ prior to plasma operation. ALT-I is inserted into the TEXTOR edge as an additional limiter, and has the ability to be moved between shots from 40 to $50 \mathrm{~cm}$ minor radius. The TEXTOR main limiters are also movable, and are normally retracted to a $48 \mathrm{~cm}$ radius during pump limiter experiments so that ALT is the primary limiter.

\section{PUMP LIMITER GEOMETRIES}

The design of the particle collection region of pump limiters can be generally be placed in two categories: open and closed geometries. Open pump limiter designs are characterized by the neutralization plate being freely exposed to the edge plasma. These designs make little or no effort to restrict the flow of neutral gas from the neutralizer plate back into the plasma. In contrast, closed geometries utiiize the plasma flow to transport the particles along entrance channels to the neutralizer plate hidden inside the limiter. The neutral gas born at the plate is restricted by a low conductance for flow back to the plasma.

ALT has three different limiter modules to examine the performance of open versus closed geometries. Each module can be mounted on the common manipulator and pumping system. The "closed" pump limiter geometry, 9 ALT-VG, with a $26 \mathrm{~cm}$ long collection throat and a low conductance for neutral gas to escape to the plasma, is shown schematically in Fig.1a. The "open" pump limiter module, ALT-FG1 in Fig.1b, has freely exposed neutralizer plates and a high conductance for gas to backflow into the tokamak. A module with an intermediate throat length of 7cm, named ALT-FG2, is shown schematically in Fig.1c. The ALT-VG has several movable plates to investigate the pumping efficiency with different throat and duct geometries, and all the modules can be closed by flaps for direct comparison as standard limiters. A direct comparison of the performance of the three different modules has recently been published. 12

Several different materials have been used for the limiter head. The ALT-FG1 utilized a simple inconel head with only toroidal curvature. The ALT-FG2 head with compound curvature was made of uncoated EK-98 graphite. The ALT-VG module utilized three different compound 
curvature head materials: TiC coated ATJ graphite, bare ATJ graphite, and a curbon-carbon composite graphite weave. During the metal limiter operation phase of TEXTOR, the inconel and TiC heads were used extensively. The total metal impurity level in the plasma during ALT experiments was essentially the same as operation with the (stainless steel) TEXTOR main limiters. This was unchanged by pump limiter operation. The bare ATJ graphite head was used in both the metal and "all graphite" phases of TEXTOR. Erosion of the heads and the deposition

of impurities was found to be similar to the results from shaped limiters in other tokamaks. ${ }^{13}$ The metal impurity level in the plasma was strongly reduced by the carbon limiters and carburization procedures. The low- $Z$ impurity level in the plasma was found to be similar for operation with ALT and with the TEXTOR main limiters.

\section{PARTICLE REMOVAL AND DENSITY CONTROL}

A useful model of tokamak fueling has been applied to the ALT performance. ${ }^{4,5}$ Reduced to its simplest form in steady state, the total electron number in the tokamak is described by

$$
N=\tau_{p}^{*} Q
$$

where $Q$ is the gas feed rate, $\tau_{p}{ }^{*}$ is the particle containment time in the vessel in terms of the recycling coefficient $R$, written as

$$
\tau_{\mathrm{p}}^{*}=\tau_{\mathrm{p}} /(1-\mathrm{R})
$$

and $\tau_{p}$ is the global particle confinement time. With hot walls, the TEXTOR recycling coefficient is close to unity. Small changes in the recycling due to pump limiter action results in substantial changes in the core density. This is illustrated in Fig. 2, where the core density is shown as a function of time during successive shots with ALT-VG as the throat opening is enlarged in steps. As more of the edge plasma flux is collected and pumped, the recycling is reduced and the density decreases. The change in $\tau_{\mathrm{p}}{ }^{*}$ as the collected current is increased by progressive insertion of ALT-VG in a separate series of shots is shown in Fig.3. The large changes in $\tau_{p}{ }^{*}$ 
during open versus closed throat comparisons at each minor radius has resulted in density reductions of over $50 \%$.

The actual amount of gas removed by a pump limiter is determined by the number of particles incident on the collection slots and the efficiency of pumping those particles. The incident particle flux depends on the location of the entrance slot, the plasma flux in the edge of the tokamak, and the number of other limiters. The efficiency of pumping the particles incident on the entrance slot is calied the removal efficiency. The fraction of the total efflux from the tokamak removed by fump limiters, or the exhaust efficiency, is also a commonly used figure of merit.

Measurements of the removal and exhaust efficiencies require knowledge of the incident ion flux into the limiter. The ion flux to the collection slots of the differen! ALT geometries, accounting for the near $30^{*}$ poloidal openings of the slots, is given ${ }^{7}$ by

$$
I=\left.\underset{2}{\Gamma_{a}}\left[\left(r^{\prime}+a\right) \lambda_{T}+\lambda_{T}{ }^{2}\right] \exp \left(-r^{\prime} / \lambda_{\Gamma}\right)\right|_{r_{1}} ^{r_{2}},
$$

where $r_{1}$ and $r_{2}$ are the radii of the entrance slot edges in $\mathrm{cm}, \Gamma_{\mathrm{a}}$ is the parallel flux at the limiter targency point in $A / \mathrm{cm}^{2}$, a is the minor radius in $\mathrm{cm}$, and $\lambda_{\Gamma}$ is the flux scrape-off-length. The slot radii for the modules are: ALT-VG; $r_{1}=2 \mathrm{~cm}$ and $r_{2}=5 \mathrm{~cm}$, and ALT-FG; $r_{1}=1 \mathrm{~cm}$ and $r_{2}=$ $3 \mathrm{~cm}$. The tangency point flux is calculated from the probe data in the scrape-off-layer. The total ion current into the entrance slot is shown in Table I for the different ALT modules. The coilection by ALT-FG2 exceeds that by the ALT-VG module when the limiters are positioned at the same radius. The difference in collection is a result of the shorter distance from the tangency point to the slot opening and two sided collection for ALT-FG2. This advantage of the ALTFG2 geometry is offset by the high heat loading on the leading edge, which is located closer to the tangency point. The leading edge heat flux limits the total power that the pump limiter can handle. 
ALT-I is nomally operated as the primary limiter in the tokamak. The effect of operation with other limiters inserted is to shorten the density and fux scrape-off lengths globally in the edge. The incident flux into the collection slot is then decreased, as seen from Eq.3. The scrape-off length scales roughly as the square root of the connection length to the other limitets when the connection length is sufficiently long. ${ }^{7}$ Direct shadowing of the pump limiter collection slot by closely positioned limiters (within about one tum tomidally) greatly decreases the incident flux. 5 Since $q=3$ in TEXTOR, extra limiters can conceivably be added without direct shadowing until about $90^{\circ}$ of the poloidal angle is subtended. Operation with other standard kimiters, to share the auxiliary heating power, for example, always is observed to decrease the exhaust efficiency and removal rate.

The removal efficiency is a function of the pumping speed in the limiter vacuum vessel. Figure 4 shows the efficiency of the different ALT modules versus the pumping speed. The removal efficiency, independent of plasma effects, is determined by the effective conductances from the neutralizer plate back to the plasma and toward the pumping system. Pump limiter designs with a high backflow conductance, illustrated by the ALT-FG1 performance, can increase the temoval efficiency up to some limit by incorporating large pumps. Ultinately, the removal efficiency will saturate at high pumping speeds when the finite conductance of the ducting from the neutralizer plate to the pumps limits the removal rate compared to the backflow. The use of the "closed" pump limiter designs results in measured removal efficiencies of over $50 \%$ for ALT. Operation with edge electron temperatures below $10 \mathrm{eV}$ results in removal efficiencies of up to $80 \%$, as will be described later. Exhaust efficiencies of $5-15 \%$ have been achieved by ALT, corresponding to a removal rate of over 10 torr-1/sec.

\section{EDGE PLASMA PARAMETERS}

A scanning Langmuir probe, a neutral Li-beam diagnostic, and a probe array on ALT are used to measure 7 the SOL parameters and characteristic e-folding lengths with the pump limiter. The flux and density haye the identical e-folding lengths of $1.8 \pm 0.2 \mathrm{~cm}$ for ALT positioned from 
42 to $46 \mathrm{~cm}$, but the $T_{e}$ profile is essentially flat. Equal flux and density e-folding lengths, and flat $T_{e}$ profiles, are characteristic of all the shots with ALT as the main limiter. The flux and density e-folding lengths increase to $2.2 \mathrm{~cm}$ when ALT is inserted to $40 \mathrm{~cm}$, and the discharge tends to disrupt easily. The longer scrape-off lengths and unstable operation may indicate a modification in the confinement associated with the reduction in safety factor, $q(a)$, with deep insertion of the limiter. Impurity scrape-off lengths of about $1.9 \mathrm{~cm}$, measured with collection probes for a limiter radius of $45 \mathrm{~cm}$, have been reported. ${ }^{14}$

The average ion saturation current measured by ion and electron side facing probes versus ALT position at one second into the pulse on the ALT-FG2 for a line averaged core density of $3.3 \times 10^{13} \mathrm{~cm}^{-3}$ is shown in Fig. Sa. The ion side flux is a factor of 2 to 3 times the electron side flux. The removal rate by the ALT pumps follows the incident flux in Fig.5a as the pump limiter is inserted. The electron temperature on the ion and electron sides is roughly equal and increases as ALT is inserted, as shown in Fig.5b. With ALT-FG2 located at $44 \mathrm{~cm}$, the variation in the collected fluxes with line averaged density is shown in Fig.6a. The flux does not change significantly with core density. However, the electron temperature, plotted in Fig.6b, decreases by about a factor of two as the density is increased from 1.5 to $4 \times 10^{13} \mathrm{~cm}^{-3}$. The removal efficiency by the pump limiter will be shown in the following sections to depend on this electron temperature change. The edge plasma is also modified by ICRH heating, as will be discussed in the next section. However, the ohmic trends for the flux to the ion and electron sides holds for auxiliary heating up to $2.4 \mathrm{MW}$, with the ion fluxes increasing roughly in proportion to the ICRH power level.

The effect of introducing pumping by ALT-I is to change the core density by reducing the recycling. 4,5 The SOL parameters follow the core density changes as described above, but are not significantly modified directly by the pumping. ${ }^{7}$ This is illustrated in Fig.7, where the ion saturation current to the ion side probe is plotted versus the line averaged density for several different pumping speeds. Despite an increase in the pumping speed from $1000 \mathrm{l} / \mathrm{sec}$ to 7,000 U/sec, the flux follows the same relationship with the core density. The SOL electron temperature 
at a given core density is primarily determined by machine conditions, such as amount of carbonization and impurity level. In general, the local value of $T_{e}$ at ALT increases by 2-5eV with pumping at a given core density. The SOL density and electron temperature are not strongly modified by pump limiter operation. Large modifications of the SOL plasma by pumping are not expected, in any case, because ALT removes only a small amount of the core efflux. The SOL plasma parameters are determined by global edge processes and not by small local changes due to the pump limiter operation.

\section{PUMP LIMITER PERFORMANCE WITH ICRH HEATING}

ALT-I is locaied $45^{\circ}$ toroidally from two half tum ICRH antennae ${ }^{15}$ with an innermost radius of $48.8 \mathrm{~cm}$. The effect of ICRH heating on the edge plasma and pump limiter 10 is illustrated in Fig.8, which shows the results from several diagnostics for ALT-FG2 at $44 \mathrm{~cm}$ during $1.5 \mathrm{MW}$ of auxiliary heating. The ICRH heating pulse results in an increased flux of particles to both sides of ALT, with the normal factor of 2 to 3 times more flux on the ion side roughly maintained. The magnitude of the increase in the incident flux is proportional to the ICRH power level. This change in edge plasma flux has been attributed to a decrease in the global particle confinement time during ICRH heating. 7 The electron temperature in the SOL also increases about a factor of 2 to 3 , with greater increases observed on the electron side. The electron side of ALT is directly facing the ICRH antennae, and larger increases in $T_{e}$ and power loading are observed on this side during heating.

The pressure rise in the ALT vacuum vessel increases with the higher incident ion fluxes observed with ICRH heating. The pump limiter, cherefore, acts to decrease the magnitude of the characteristic density build-up during ICRH, and generally results in higher ICR.H powers coupled to the plasma. The removal rate by the pumps is found to increase more slowly than the particle flux, indicating that the efficiency of the pump limiter is degraded. This effect is consistent the removal efficiency dependence on electron temperature ${ }^{16}$ previously observed in the ohmic phase, which will be discussed later. The increase in edge electron temperature with 
ICRH heating enhances plasma neutral interactions in the pump limiter entrance throat, modifying the neutral trapping efficiency of the limiter.

\section{VI, PLASMA CONFINEMENT EFFECTS}

The energy and particle confinement times in the core plasma have been monitored during pump limiter operation in the ohmic and ICRH auxiliary heating phases. The energy confinement time during ohmic heating in TEXTOR is linearly proportional to the plasma density, ${ }^{17}$ following standard Alcator scaling with both the main limiters and with ALT. During ICRH heating with the main TEXTOR limiters, $\tau_{E}$ degrades with heating power and follows the L-mode scaling. ${ }^{15}$ Operation with ALT-I is found not to change this scaling during auxiliary heating. In Fig.9, the value of $\tau_{E}$, normalized to the corresponding ohmic value of $\tau_{E}$ for the line averaged density measured during heating, is plotted versus the total input power to the plasma. The data plotted includes a density scan from 1 to $4 \times 10^{13} \mathrm{~cm}^{-3}$ at each radius, indicating that no density đependence is found. Operation with both open and closed flaps (particle exhaust and standard limiter conditions) at several different limiter positions is shown not to enhance the energy confinement time.

The particle confinement time has been estimated both from the probe studies ${ }^{7}$ and optical spectroscopy. 18 The value of $\tau_{p}$ is found to be linearly proportional to the plasma densiry. Estimates of the ionization mean-free-path in the edge of TEXTOR indicate that the "opaque" edge plasma observed to decrease $\tau_{p}$ at higher densities in other tokamaks has not been achieved in TEXTOR. During both ohmic and auxiliary heating, $\tau_{\mathrm{p}}$ is observed to scale with $\tau_{\mathrm{E}}$. In fact, the values of $\tau_{p}$ and $\tau_{E}$ are on the same order, and remain so during heating. Pump limiter operation has not been observed to affect the global confinement times in TEXTOR.

\section{DMPURITY REMOVAL}

The ability of pump limiters to remove impurities has been investigated in TEXTOR 5,6 and ISX-B 19 experiments. In TEXTOR, helium removal was studied with the ALT modules. In 
these experiments, helium was injected either into the pre-fill or during the discharge, and was detected in the pump limiter vacuum vessel by in RGA. The concentration of He in the discharge ranged from about 1 to $10 \%$, and was estimated from the increase in the line averaged density with helium injection. Figure 10 shows the $\mathrm{He}$ to $\mathrm{H} \mathrm{ratio}^{6}$ in the plasma and pumping vessel as a function of time for a single shot. For He concentrations of about $2.5 \%$ in this shot, the removal and transport of He into the pumping chamber is nearly the same as observed for hydrogen. For higher He concentrations ( $10 \%$ ), the removal rate of $\mathrm{He}$ compared to $\mathrm{H}$ was found to decrease by about a factor of two. While this removal rate dependence on concentration is not understood at this time, the amount of helium actually removed suggests that pump limiters can adequately control the He "ash" in a fusion device, 6

\section{LIMFTER HEAT FLUX}

The bulk temperature rise of the limiter head, which indicates the total power loading per discharge, is measured by thermocouples imbedded in the graphite heads. Infared thermography measurements 20 allow a more quantitative power estimate to be made. The surface temperature profile along the center of the limiter from the leading edge to the tangency point is shown in Fig.11. As expected, the leacing edge has the highest surface temperature and corresponding heat flux. The compound curvature of the head is found to spread the heat uniformly over the surface as predicted in the original design.?

With ohmic heating, the power deposition to the limiter heal' increases with decteasing plasma density. From the thermocouple and IR camera measurements, the total power to ALT ranges from 10 to $50 \%$ of the ohmic power depending on the limiter position, plasma density, and $\mathrm{Z}_{\mathrm{eff}}$. Deep insertion of ALT to a $=40 \mathrm{~cm}$ results in the deposition of $30-50 \%$ of the ohmic power even for low $Z_{\text {eff }}$ shots. 'ithe heat flux contours with ICRH heating are generally similar to those found in the ohmic phase.

A relatively simple model ${ }^{7}$ has been successfully used to calculate the heat flux to the ALT limiter. The probes measure a constant density scrape-oft length, $\lambda_{n}$, to within about $1-2 \mathrm{~cm}$ of 
the ALT tangency point, and a flat electron temperature profile. Recent analysis indicates that strong variations in the electron temperature exist at the limiter surface near the tangency point. 21 Additionally, Thomson scattering measureinents show electron temperatures of 30-50eV near the tangency point of the limiter. A reasonable model of this electron temperature variation is

$$
T_{e}^{\prime}(r)=T_{e 1} \exp \left[-(r-a) / \lambda_{T}\right]+T_{e 2},
$$

a pedestal model with $\mathrm{T}_{\mathrm{e} 2}$ equal to the probe measurements in the $\mathrm{SOL}, \mathrm{T}_{\mathrm{el}}+\mathrm{T}_{\mathrm{e}}$ equal to the tangency point electron temperature estimate, and $\lambda_{\mathrm{r}}=1 \mathrm{~cm}$. This approximate value of $\lambda_{\mathrm{T}}$ is suggested by the heat flux measurements made on the face of ALT with IR cameras. The probe and $\mathrm{Li}$ beam measurements give

$$
n(r)=n_{a} \exp \left[-(r-a) / \lambda_{a}\right] \text {. }
$$

which is assumed to be valid up to the tangency point. Since the flux scales as $n T_{e}^{1 / 2}$, the radial variation in flux is

$$
\Gamma(r)=\Gamma_{a}\left(T_{e 1} / T_{e}(a)\right)^{1 / 2} \exp \left[-(r-a) / \lambda_{n}\right]\left\{\exp \left[-(r-a) / \lambda_{T}\right]+T_{e 2} / T_{e 1}\right)^{1 / 2},
$$

valid for $r \geq a$.

The parallel heat flux density to the ALT limirer is given by

$$
\mathrm{q}(\mathrm{r})=\gamma_{\mathrm{s}} \mathrm{T}_{\mathrm{e}}(\mathrm{r}) \Gamma_{\mathrm{p}}(\mathrm{r}), \quad \mathrm{r} \geq \mathrm{a}
$$

where $\gamma_{S}$ is the total sheath transmission fact $;$ for ions and electrons. Assuming approximately equal ion and electron temperatures, $\gamma_{\mathrm{S}}$ is calculated 22 to be 6.5 . Poloidal symmetry of $n_{\mathrm{e}}$ and $\mathrm{T}_{\mathrm{e}}$ over the limiter will be assumed in this calculation. While this is measured in the SOL by the probes on ALT, variations near the tangenc;' point may lead to some error in the calculated power. Utilizing the pedestal model described above, the total heat flux to the limiter is

$$
\mathrm{Q}=4.5 \int \Gamma_{\mathrm{p}} \exp \left(x / \lambda_{\Gamma}\right) \mathrm{T}_{\mathrm{el}} \mathrm{l}^{3 / 2} \mathrm{~T}_{\mathrm{e}}(\mathrm{a})^{-1 / 2} \exp \left[-(\mathrm{r}-\mathrm{a}) / \lambda_{\mathrm{n}}\right]\left(\exp \left[-(\mathrm{r}-\mathrm{a}) \lambda_{\mathrm{T}}\right]+\mathrm{T}_{\mathrm{e} 2} / \mathrm{T}_{\mathrm{e}]}\right)^{3 / 2} \mathrm{r} \mathrm{dr} .(8)
$$


The results of a numerical integration of Eq.8 are included in Table $I$ for a $=44 \mathrm{~cm}$. Estimates of the power to ALT at this radius from thermocouple measurements of the bulk temperature rise indicate that ALT typically receives 10-30 percent of ohmic power. This is in reasonable agreement with the values calculated in $\mathrm{T}_{3} \mathrm{ble} I$ for $\mathrm{T}_{\mathrm{e}}(\mathrm{a})$ on the order of $50 \mathrm{eV}$.

Detailed analysis 23 of the heat flux to ALT, as measured by an IR camera, 20 has been made for the limiter positioned at $40 \mathrm{~cm}$. ALT is typically found to collect $150 \mathrm{~kW}$ of power during this deep insertion into the plasma. The calculated power to ALT at this position is shown in Fig.12. The electron temperature required at the tangency point to predict the measured $150 \mathrm{~kW}$ power deposition is about $50-60 \mathrm{kV}$, in goud agreement with the $\mathrm{T}_{\mathrm{e}}$ values estimated from Thomson scattering.

\section{PUMP LIMITER MODELING}

Understanding of the physics of pump limiter operation has been increased by modeling of the recent experiments. In contrast to divertors, the plasma parameters in the pump limiter entrance channel. are not significantly modified, compared to the tokamak edge plasma, by the local recycling at the neutralization plates. This recent result has led to the renewed application of 3-D Monte-Carlo neutral gas codes, whith assume constant plasma parameters, to model pump limiter performance. Monte Carlo sin:ilations of the ALT pump limiters have been reported, 24,25 but the codes were only used to examine the recycling in the pump limiter thraat region and the efficiency for a given set of conditions.

Scaling of the particle removal rate with edge plasma density and electron temperature has recently been studied. 16 Figure 13 shows the calculated pressure rise in the ALT vacuum vessel, for the case of no active pumping, as a function of the flux incident on the entrance slot. The modeling indicates that at a constant electron temperature, the pressure rise is linear with the incident flux. This was confirmed experimentally during ALT experiments. 16 The code also predicts that the pressure rise is higher for a lower electron temperature. The measured removal efficiency, or the pressure rise for a constant incident flux in the ALT experiments, was strongly 
affected by changes in the electron temperature, as seen in Fig.14. The similar behavior predicted by the code indicates that atomic physics processes contribute to the pump limiter efficiency for a given geometry. In this case, ionization and dissociation of recycled neutrals result in an enhanced escape of particles from the neutralizer region to the plasma. Operation of the pump limiters in edge plasma with $T_{e}$ less than $10 \mathrm{eV}$ results in an increase in the removal efficiency due to a minimization of the nlasma-neurral gas interaction effects. An examination of the non-linear pressure rise with incident flux reported in past pump limiter experiments indicates that pressure increases generally coincided with an electron temperature drop. The non-linear pressure increase was attributed to "plasma-plugging", but is actually now understood to be a removal efficiency change due to atomic physics processes.

The Monte Carlo modeling also illustrates the effect of the throat iength on the removal efficiency. Neutral density profiles of hydrogen molecules along the ALT-VG entrance channel have been produced for several possible values of the plasma electron temperature. The neutral gas density, from molecules produced at the neutralization plate, is strongly attenuated toward the entrance by ionization in the throat as the electron temperature increases. The length of the channel can be chosen, if the plasma temperanure and density are known or estimated, to significantly reduce the neutral gas backflow to the core plasma.

\section{$\mathrm{X}$. CONCLUSIONS}

ALT-I experiments have clearly demonstrated the ability of pump limiters to control the plasma density in a high recycling tokamak. This is achieved by the exhausting of up to $15 \%$ of the core efflux. Proper pump limiter designs with restricted entrance geometries to reduce the backflow of the neutralized gas to the plasma results in removal efficiencies of over $50 \%$ for a wide range of operating conditions. Removal efficiencies of up to $80 \%$ have been observed for the case of very low edge electron temperatures $(<10 \mathrm{eV})$ where the plasma-neutral gas inceractions are minimized.

Experiments with ALT during ohmic heating indicate that $\tau_{P}$ and $\tau_{E}$ are proportional to $n_{e}$ over 
the density range available in TEXTOR. With auxiliary heating, $\tau_{E}$ is found to follow L-mode scaling independent of pump limiter aperation. The values of $\tau_{p}$ and $\tau_{E}$ are observed to be of the same order, and follow each other during auxiliary heating. The decrease in $\tau_{p}$ during ICRH heating results in much greater incident ion fluxes on the entrance slots, and currespondinf, higher removal rates. This effect reduces the characteristic core density rise during ICRH heating by raising the exhaust rate.

Measurements of the power deposition on ALT by IR cameras indicate that the compound curvature of the limiter is effective in distributing the heat over the limiter surface. As expected, the leading edge has the highest surface temperature, which limits the maximum power that the pump limiter can handle. Impurity removal experiments demonstrate that helium exhaust can be achieved with a pump limiter. Removal rates of helium to the ALT pumping vessel at roughly 50-100\% of the hydrogen removal rates was observed for core helium concentrations of 1-10\%.

Finally, pump limiter operation does not directly affect the SOL plasma during $r$ 'imic heating. Operation with pumping and particle removal decreases the line averaged core p.asma density by changing the recycling at the boundary. The global particle confiuement, the flux to the limiter, and the edge $T_{e}$ follow the changes in the core density.

\section{ACKNOWLEDGMENTS}

The authors would like to thank the TEXTOR team for support of these experiments, the scientists from the Laboratorie de Physique des Plasmas, Ecole Royale Militaire, Brussels, Belgium for the ICRH system operation, and Mr. K. A. Andrews, Mr. L. Brown, Mr. S. Guthrie, Mr. A. Hiller, Mr. V.Low, and Mr. T.Sketchely for technical support of the ALT-I project.

* Work supported by the U.S. Department of Energy under contract \#DE-F603-85 ER 51069, and by Sandia National Laboratories under contract \$51-7706. 
TABLE I. Total ion current into the ALT module openings for several standard positions. The edge ion flux is insensitive to variations in the core density in TEXTOR.

\begin{tabular}{|c|c|c|c|c|c|}
\hline MODULE & $\begin{array}{r}a \\
(\mathrm{~cm})\end{array}$ & $\begin{array}{c}x \\
\text { (cm) }\end{array}$ & $\begin{array}{c}\lambda_{\Gamma} \\
(\mathrm{cm})\end{array}$ & $\begin{array}{c}\text { Geometric Area } \\
\left(\mathrm{cm}^{2}\right)\end{array}$ & $\begin{array}{l}\text { Collected Current } \\
\text { (Amperes) }\end{array}$ \\
\hline ALT-VG & 40 & 3.5 & 2.25 & 69 & 102 \\
\hline ALT-VG & 42 & 3.5 & 1.8 & 69 & 88 \\
\hline ALT-VG & 44 & 3.5 & 1.8 & 69 & 52 \\
\hline ALT-FG2 & 43 & 2.0 & 1.8 & 96 & 90 \\
\hline ALT-FG2 & 44 & 2.0 & 1.8 & 96 & 65 \\
\hline
\end{tabular}

TABLE II. Heat fluxes calculated for ALT-FG2 operation for reasonable values of the electron temperatures in the pedestal model.

$\mathrm{a}=44 \mathrm{~cm} \quad \lambda_{\mathrm{n}}=1.8 \mathrm{~cm} \quad \mathrm{P}_{\mathrm{OH}}=350 \mathrm{~kW} \quad \mathrm{~T}_{\mathrm{e}}(\mathrm{a})=\mathrm{T}_{\mathrm{e} 1}+\mathrm{T}_{\mathrm{e} 2}$

$\Gamma_{\mathrm{p}}=1.3 \mathrm{~A} / \mathrm{cm}^{2}$ (ion plus electron side fluxes)

\begin{tabular}{|c|c|c|c|c|c|}
\hline $\begin{array}{l}T_{e 1} \\
(e V)\end{array}$ & $\begin{array}{l}\mathrm{T}_{\mathrm{e} 2} \\
(\mathrm{eV})\end{array}$ & $\begin{array}{l}\lambda_{\mathrm{T}} \\
(\mathrm{cm})\end{array}$ & $\begin{array}{c}\Gamma_{\mathrm{a}} \\
\left(\mathrm{A} / \mathrm{cm}^{2}\right)\end{array}$ & $\begin{array}{l}\text { Total Heat Flux } \\
\text { (kilowatts) }\end{array}$ & $\begin{array}{l}\text { \%Ohmic } \\
(\%)\end{array}$ \\
\hline 15 & 0 & $\infty$ & 4 & 21.4 & 6.1 \\
\hline 25 & 15 & 1 & 5.8 & 41.1 & 11.7 \\
\hline 35 & 15 & 1 & 6.3 & 49.5 & 14.1 \\
\hline 85 & 15 & 0.5 & 9.7 & 78.1 & 23.3 \\
\hline
\end{tabular}




\section{REFERENCES}

1. P.K. Mioduszewski, J.Nucl.Mat., 1118.112 (1982) 253.

2. R.W. Conn, J.Nucl.Mat.,128\&129 (1984) 407.

3. D.M. Goebel, Fusion Technology 10 (1986) 761.

4. A.E.Pontau, et al., J. Nucl. Mat. $128 \& 129$ (1984) 434.

5. K.H.Dippel, et al., Plasma Physics and Controlled Nucl. Fusion Research (Proc. 10th Intl. I4EA Conf., London 1984), Vol. 1, LAEA Vienna (1985).

6. G.J.Thomas, et al, J. Vac. Sci. Tech, Proc. American Vac. Soc., Fusion Tech. Div. Meeting, Houston, Texas (1985).

7. D.M.Goebel, et al., Plasma Physics and Controlled Fusion 29 (1987) 473.

8. J.Schluter, et al., and V.P.Bhatnagar, et al., Nucl. Fusion, 25, 1065 (1985).

9. R.W. Conn, et.al., Proc. 12th Symp. Fusion Tech. Jülich, FRG (SOFT) Pergamon Press I (1983) p.497.

10. W.K.Leung, et al., submitted to Plasma Physics and Controlled Fusion.

11. J. Winter, et al., J.Nucl.Mat., $128 \& 129$ (1984) 841.

' 12. K.H. Finken, et. al., J.Nucl. Mat., 145\&147 (1984).

13. R. McGrath, J.Nucl. Mat., 145\&147 (1984).

14. R.A.Zuhr and W.R.Wampler, J. Vac. Sci. Tech., Proc. 3 lst Natl. Symp. American Vac. Soc., Reno, Nevada, Dec. 4-7, 1984.

15. A.M.Messiaen, et.al.. Plasma Physics and Controlled Fusion, 28, 71 (1986).

16. G.A. Campbell, et.al., UCLA Report \#PPG-958, March 1986.

17. G. Waidmann, et al., Plasma Physics and Controlled Nucl. Fusion Research (Proc. 10 Intl. IAEA Conf., London 1984), Vol. 1, IAEA Vienna (1985).

18. U.Samm, et al., Proc. IEEE Conf.Plasma Sci., Austin, Texas, Nov. 1985, to be published in IEEE Joumal of Plasma Science. 1986.

19. R.C. Isler, et al., Nucl. Fusion 25 (1985) 1480. 
20. G.J.Thomas, et.al., J.Nucl. Mat., 145\&147 (1984).

21. A.K.Prinja and R.W.Conn, J. Nucl. Mat. $128 \& 129$ (1984) 135.

22. P.C.Stangeby, Phys. Fluids, 28, 644 (1985).

23. R. McGrath, Sandia National Laboratories, to be published.

24. C.D.Boley, et al., J. Nucl. Mat. 121 (1984) 316.

25.D.Reiter and A. Nicolai, J. Nucl. Mat. 128\&129 (1984). 


\section{FIGURE CAPTIONS}

1. ALT-I module heads showing schematically the different entrance designs for the open and closed pump limiter geometries.

2. Plasma density versus time on successive shots for $A L T-V G$ at $a=44 \mathrm{~cm}$, where the entrance slot was slowly opened. Increased article exchaust decreases the recycling and reduces the core density.

3. The reduction in $\tau_{\mathrm{p}}{ }^{*}$ as ALT is inserted deeply into the plasma.

4. Removal efficiency of the different limiters modules versus pumping speed. The efficiency resulss from a competition between pumping speed for the ducts and backflow conductance from the neutralizer to the plasma.

5. (a) $I_{\text {sat }}$ from the entrance probes versus ALT-FG2 position, (b) electron temperature versus ALT-FG2 position.

6. (a) $I_{\text {sat }}$ versus core density for $\mathrm{ALT}-\mathrm{FG} 2$ at a $=44 \mathrm{~cm}$, (b) electron temperature versus core density for ALT-FG2 at $a=44 \mathrm{~cm}$.

7. Flux to the ALT entrance probe versus pumping speed, indicating that paracle removal results in insignificant modification in the edge plasma parameters for a given core density.

8. Results from various diagnostics versus time for a shot witb ALT and the main limiters at $46 \mathrm{~cm}$ and with $1.5 \mathrm{MW}$ ICRH, (a) core density, (b) ion side flux, (c) ion side $T_{e}$, (d)pressure rise,(e) electron side flux, (f) electron side $T_{e}$.

9. Energy confinement time normalized to the ohmic values at the same density versus total power input for several positions of ALT. Pumping had no observable effect on $\tau_{E^{\prime}}$

10. Helium concentration in the core plasma and pumping vessel versus time, indicating that helium transport to the pumping locations is comparable to the hydrogen transport.

11. ALT su. iace temperature profile showing the higher leading edge temperatures.

12. Deposited power calculated from the pedestal model versus $T_{e}(a)$. Taking $T_{e}(a)=50 e V$ from 
Thomson scattering data gives good agreement with the $150 \mathrm{~kW}$ measured by IR cameras. 13. Calculated prassure rises in ALT without pumping from Monte Carlo simulation, versus the total inciden* ion flux into the entrance. At a constant electron temperarure, the removal efficiency is constant and the pressure is linearly proportional to the flux into the limiter.

14. Measured and calculated pressure rises in ALT with $6000 \mathrm{l} / \mathrm{sec}$ of pumping, for a constant incident flux, versus the throat plasma electron temperature from probes. The code calculation and the experiment show efficiency increases for lower electron temperatures, indicating tha ${ }^{*}$ atomic physics processes in the throat affect the removal efficiency. 


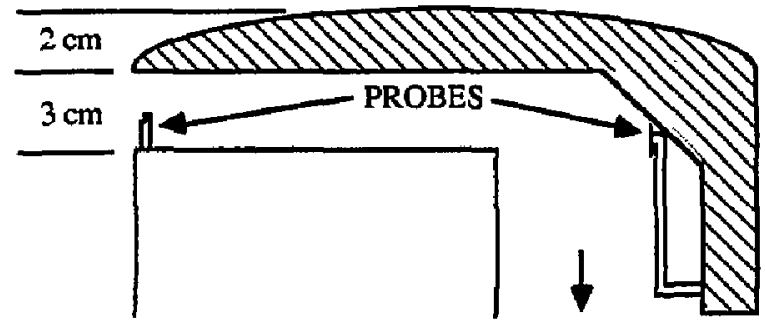

TO PUMPS
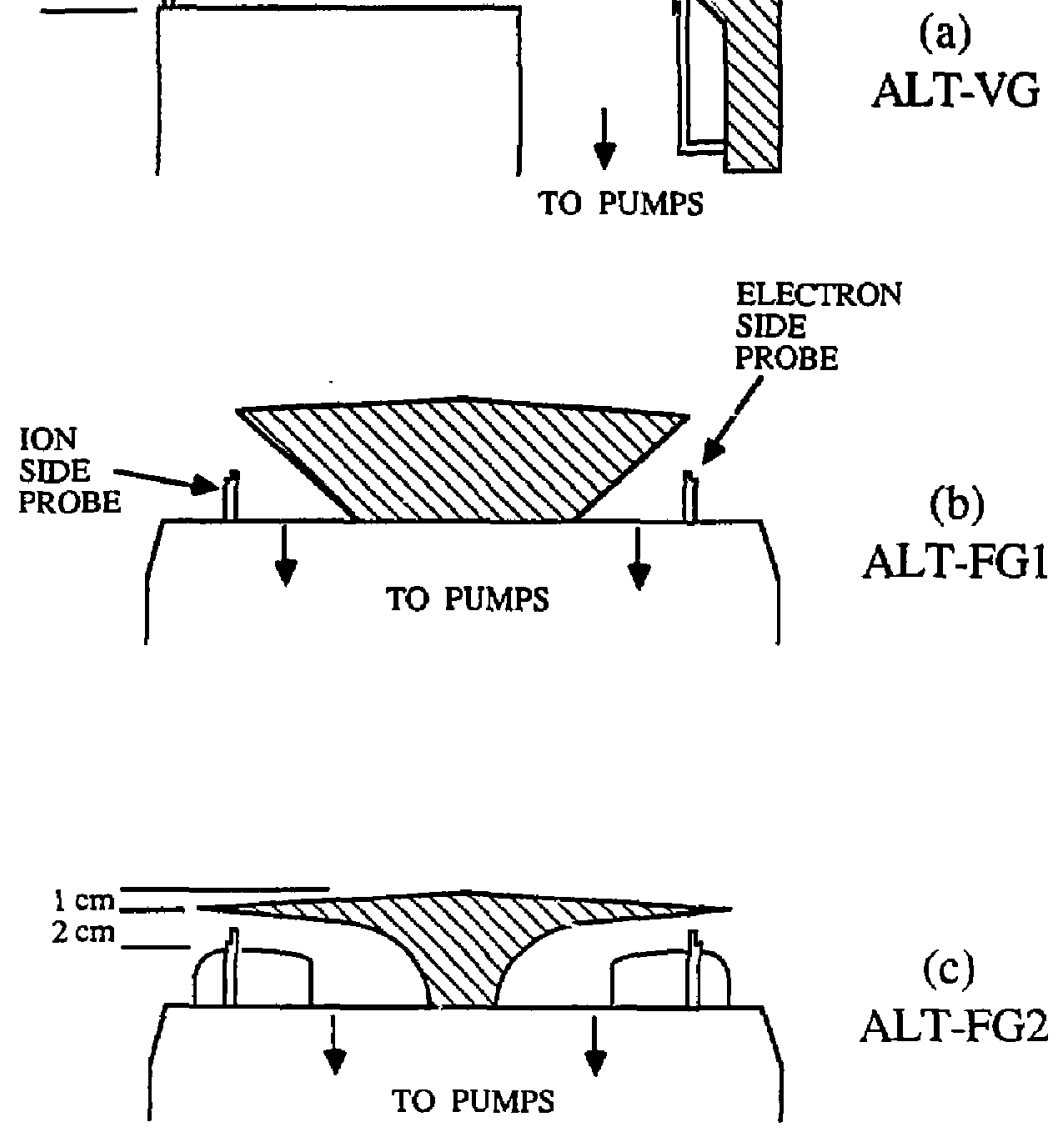

(c)

ALT-FG2

Figure 1 


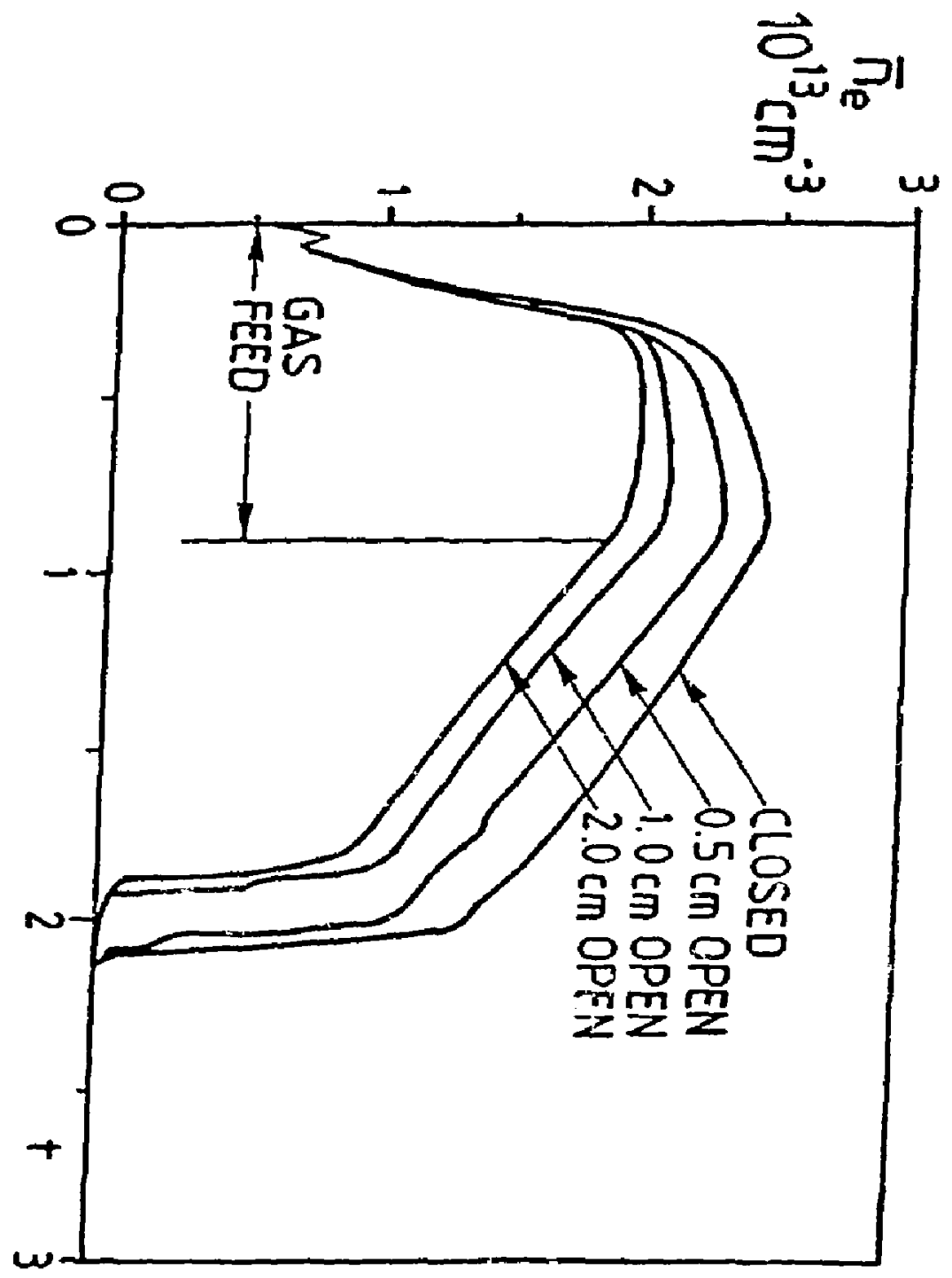




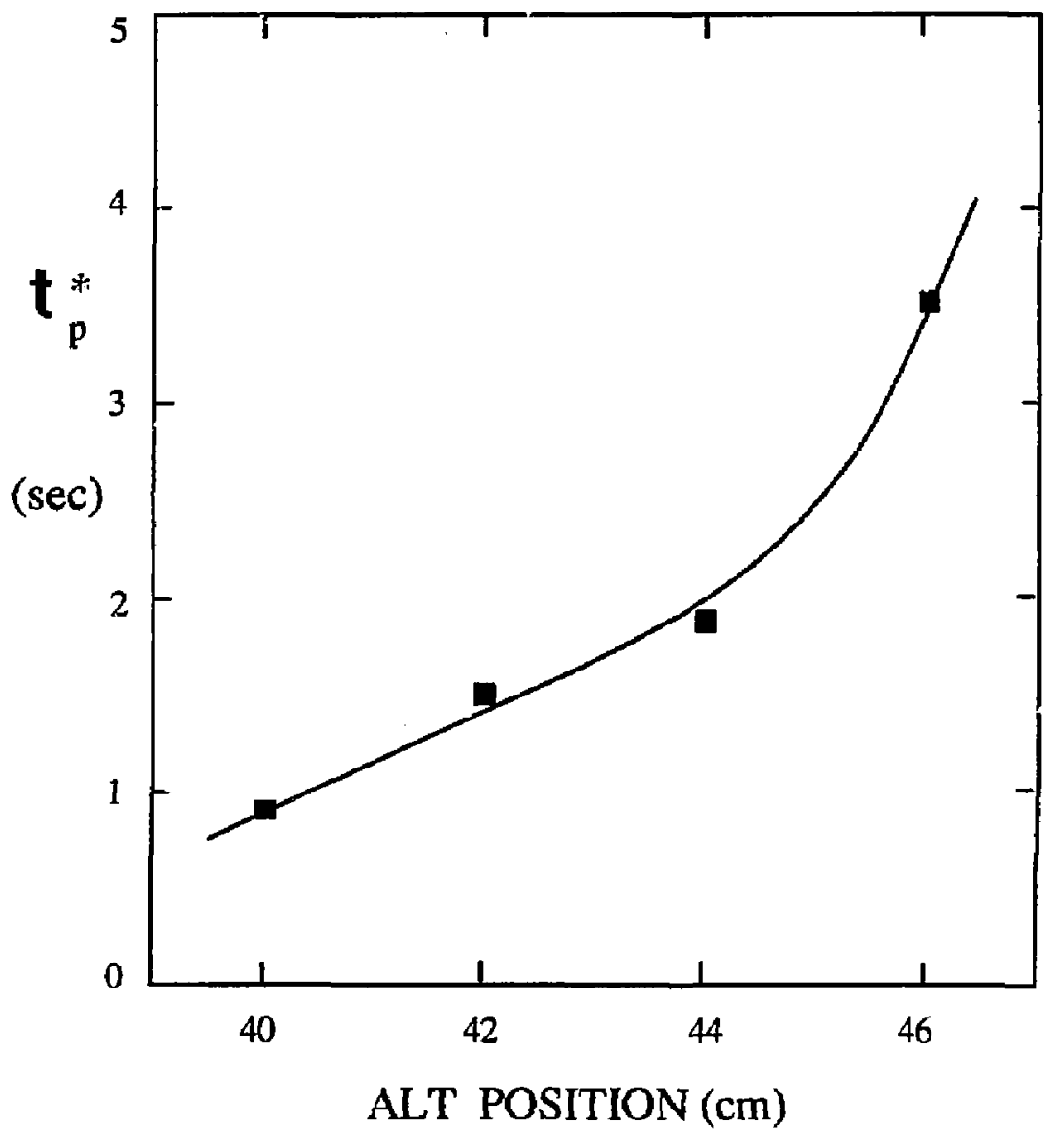

Figure 3 


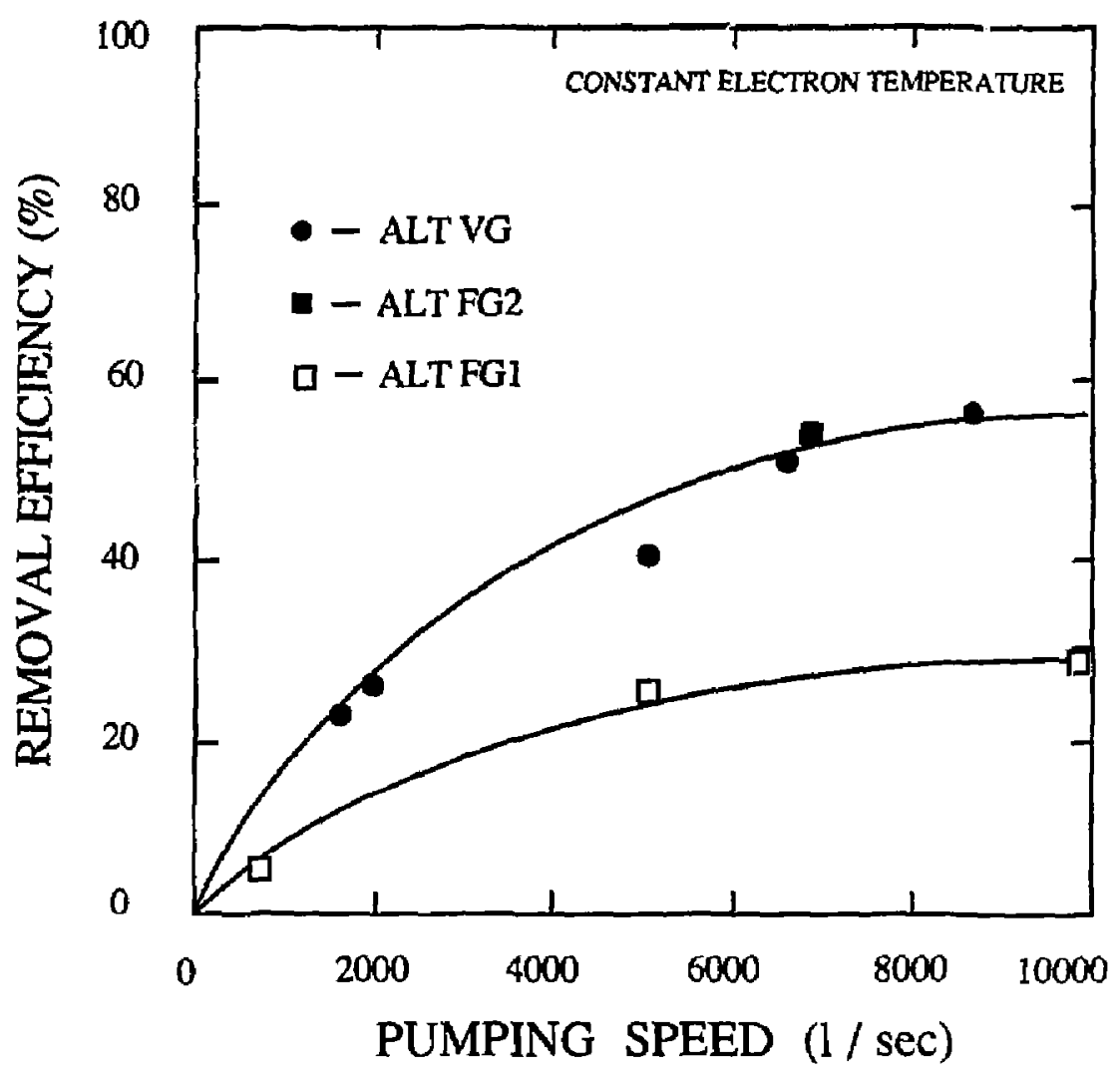

Figure 4 


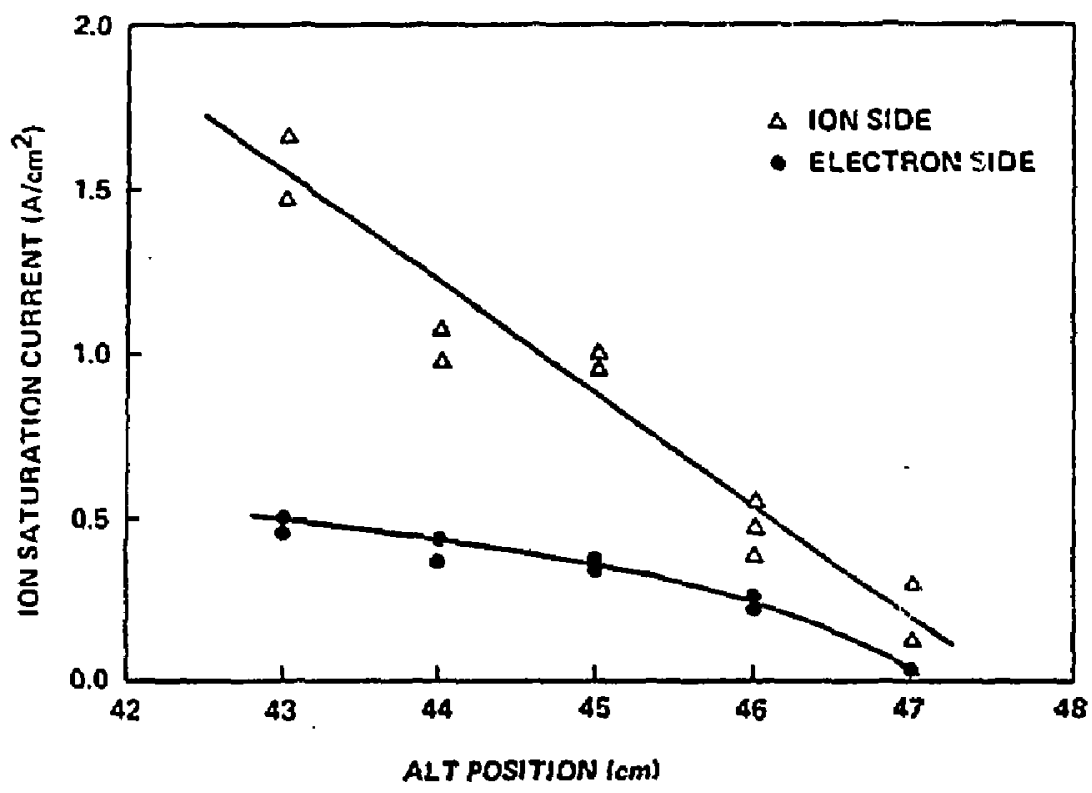

(a)

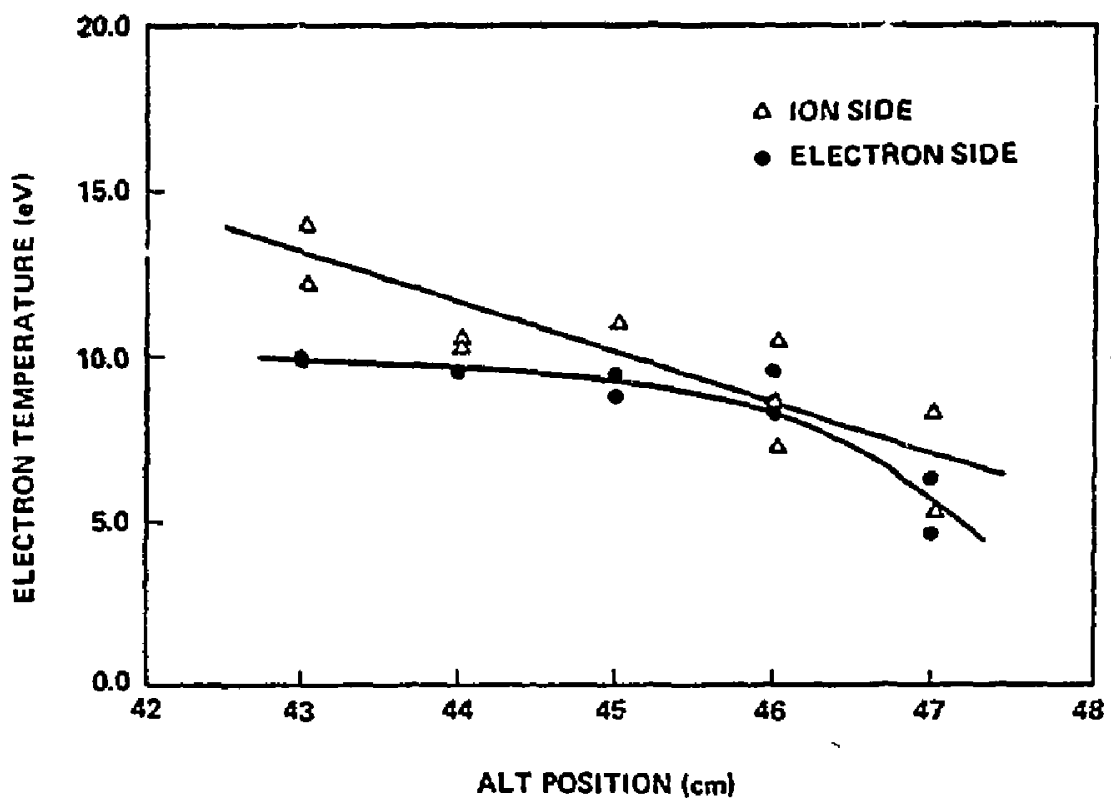

(b)

Figute 5 


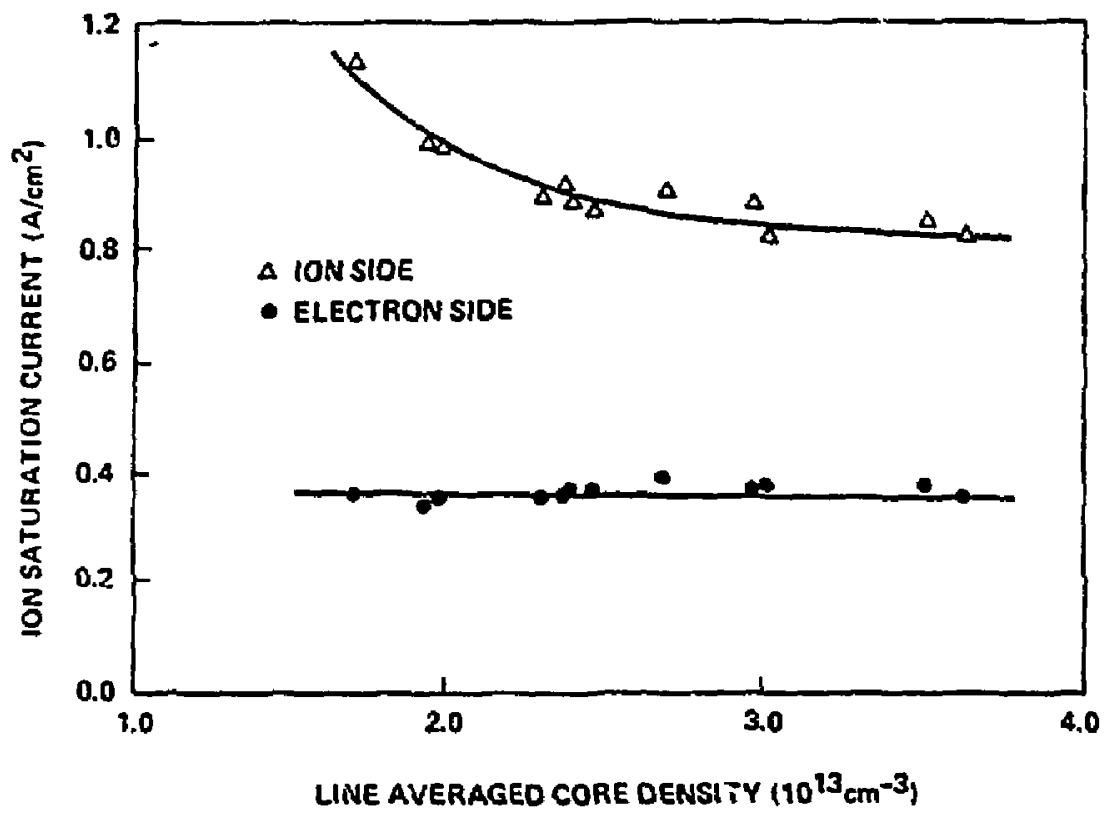

(a)

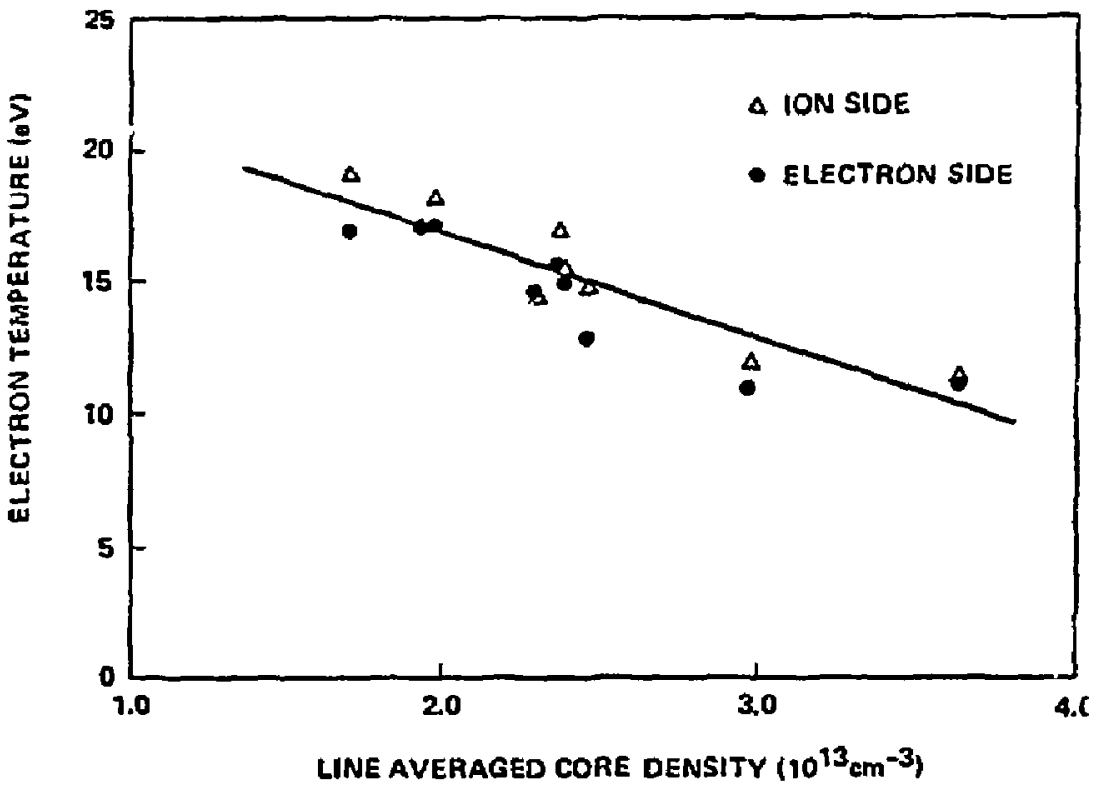

(b)

Flgure 6 


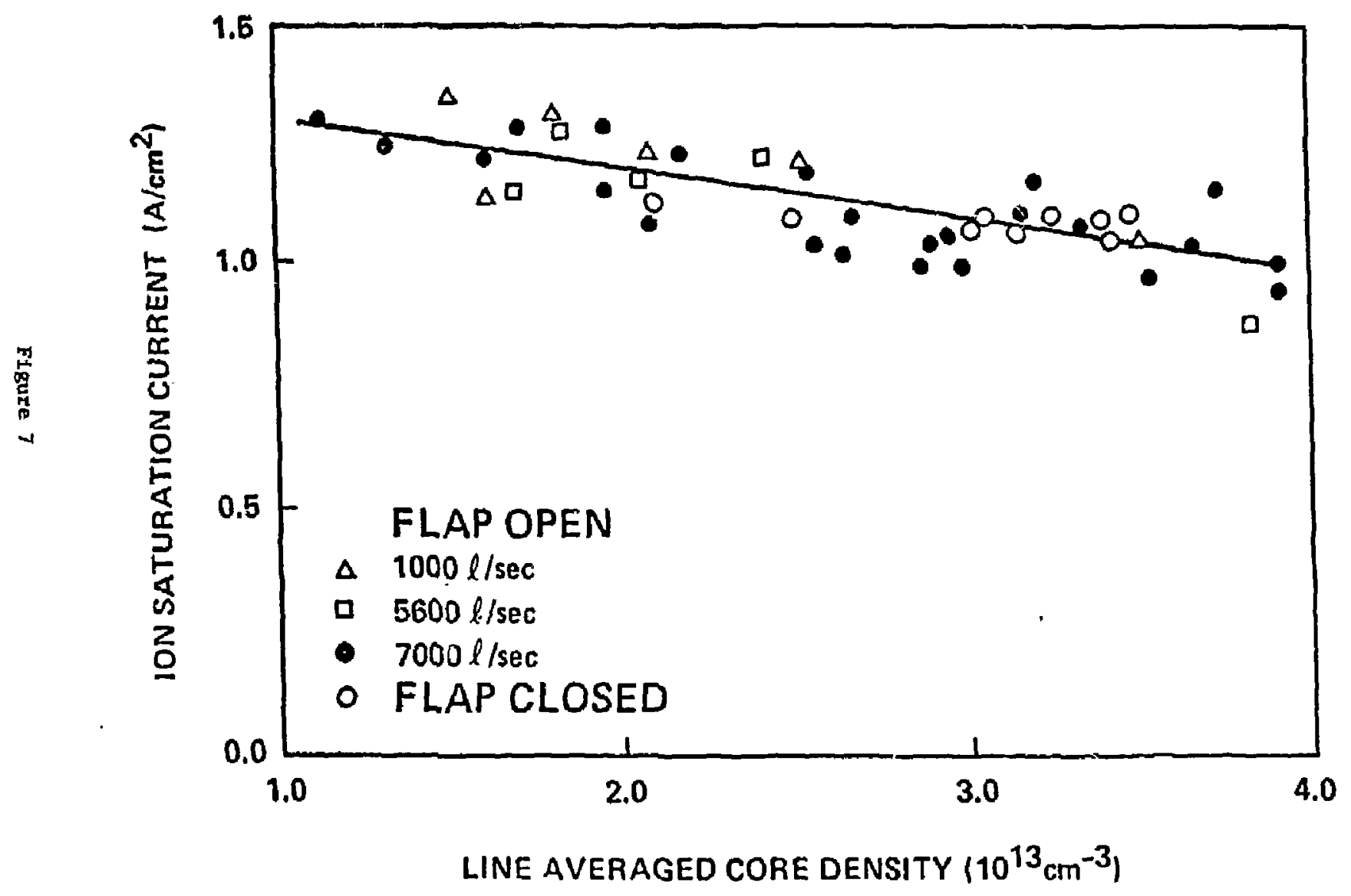




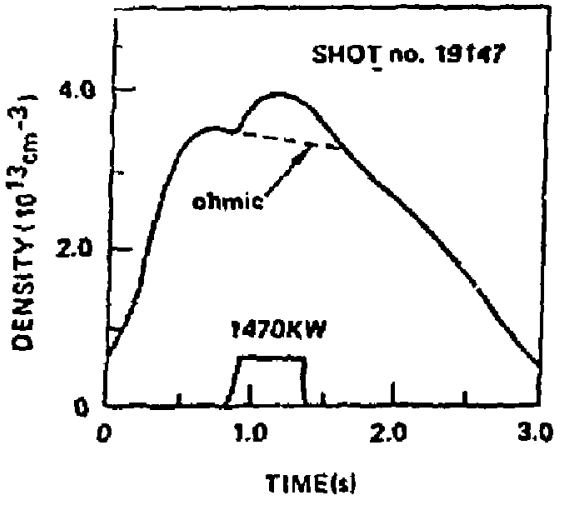

(a)

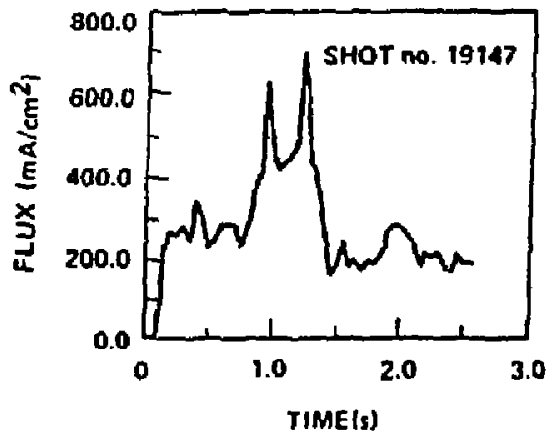

(b)

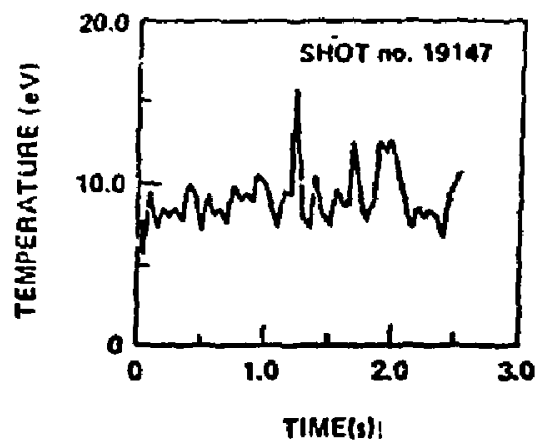

(c)

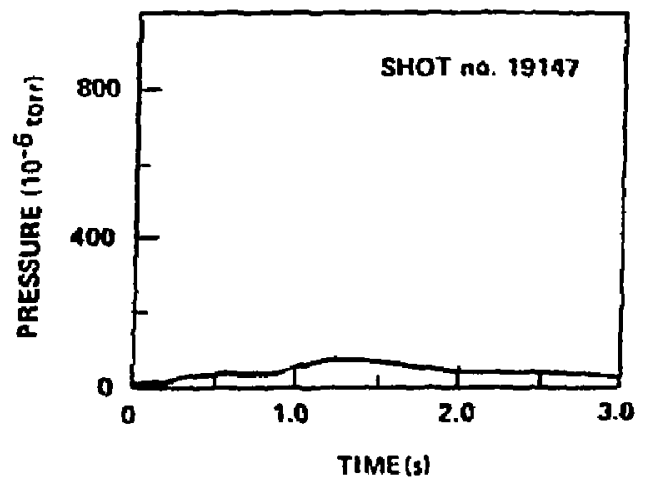

(d)

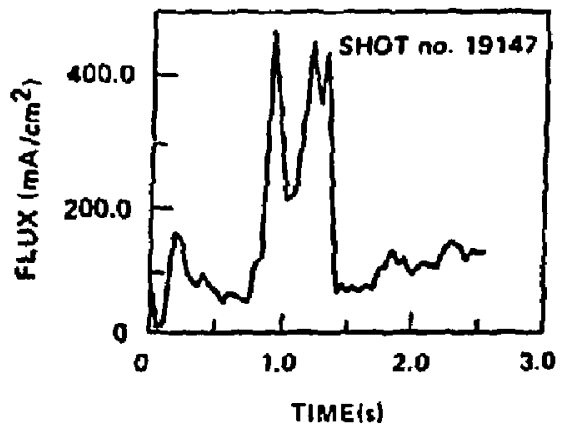

(e)

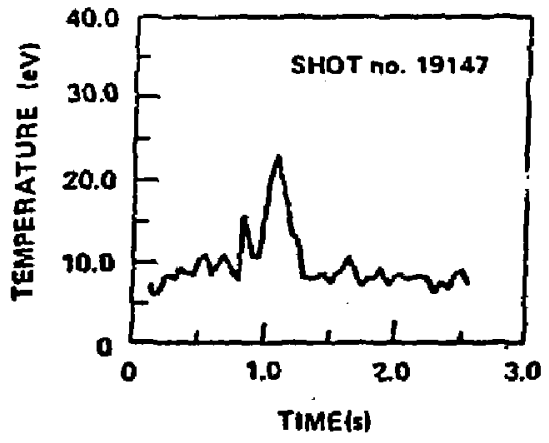

(1) 


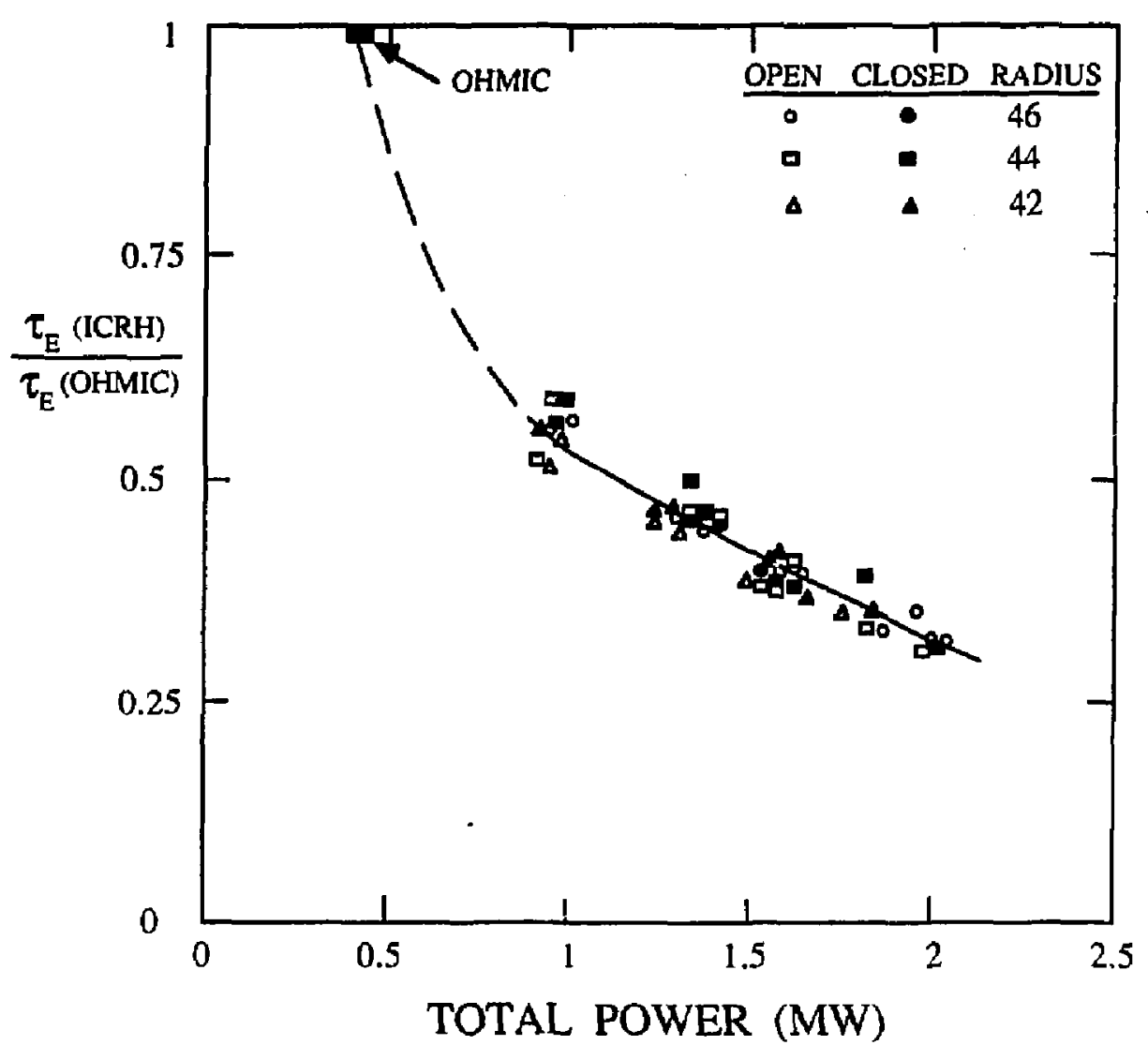

Figure 9 


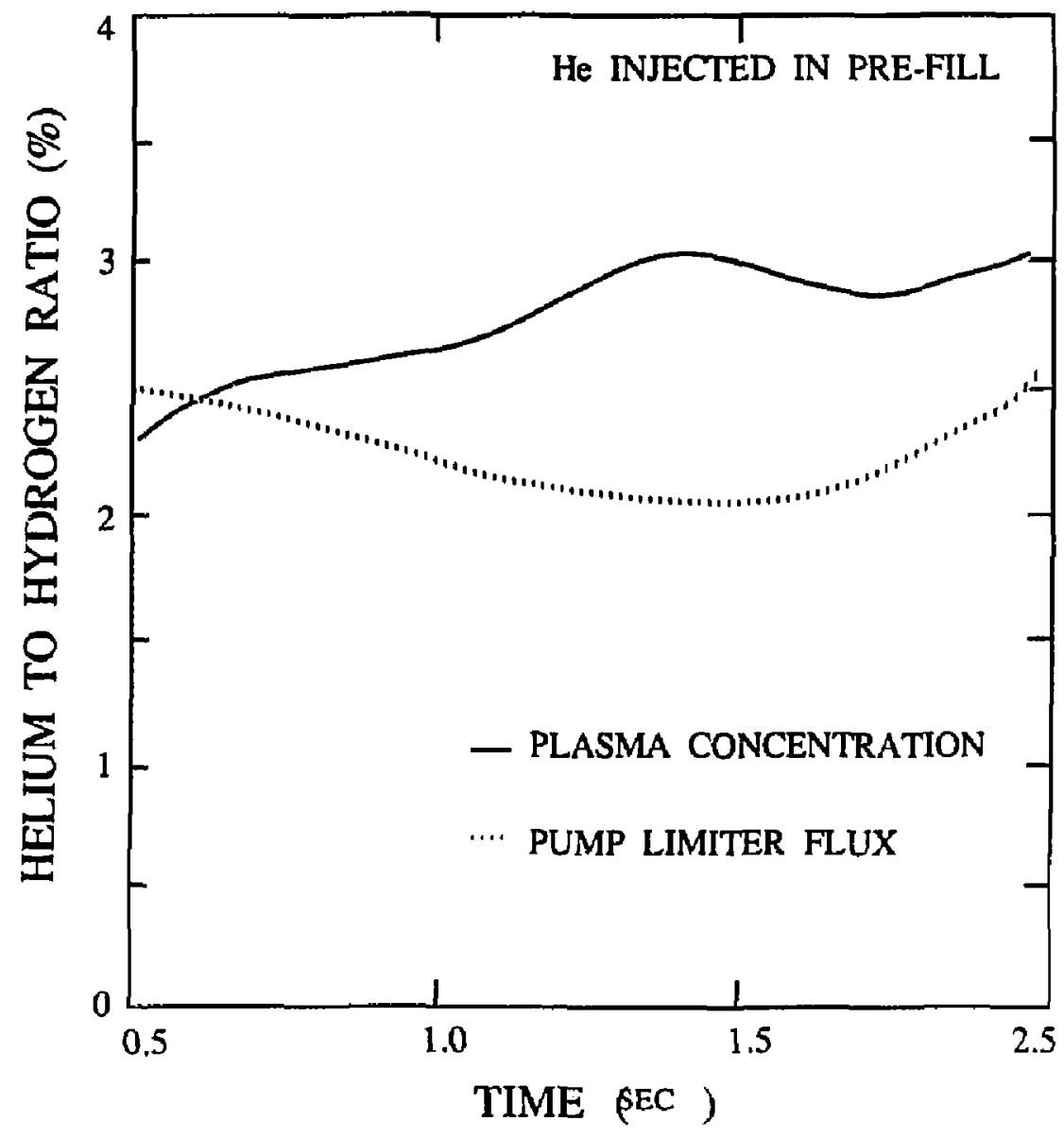

Figure 10 


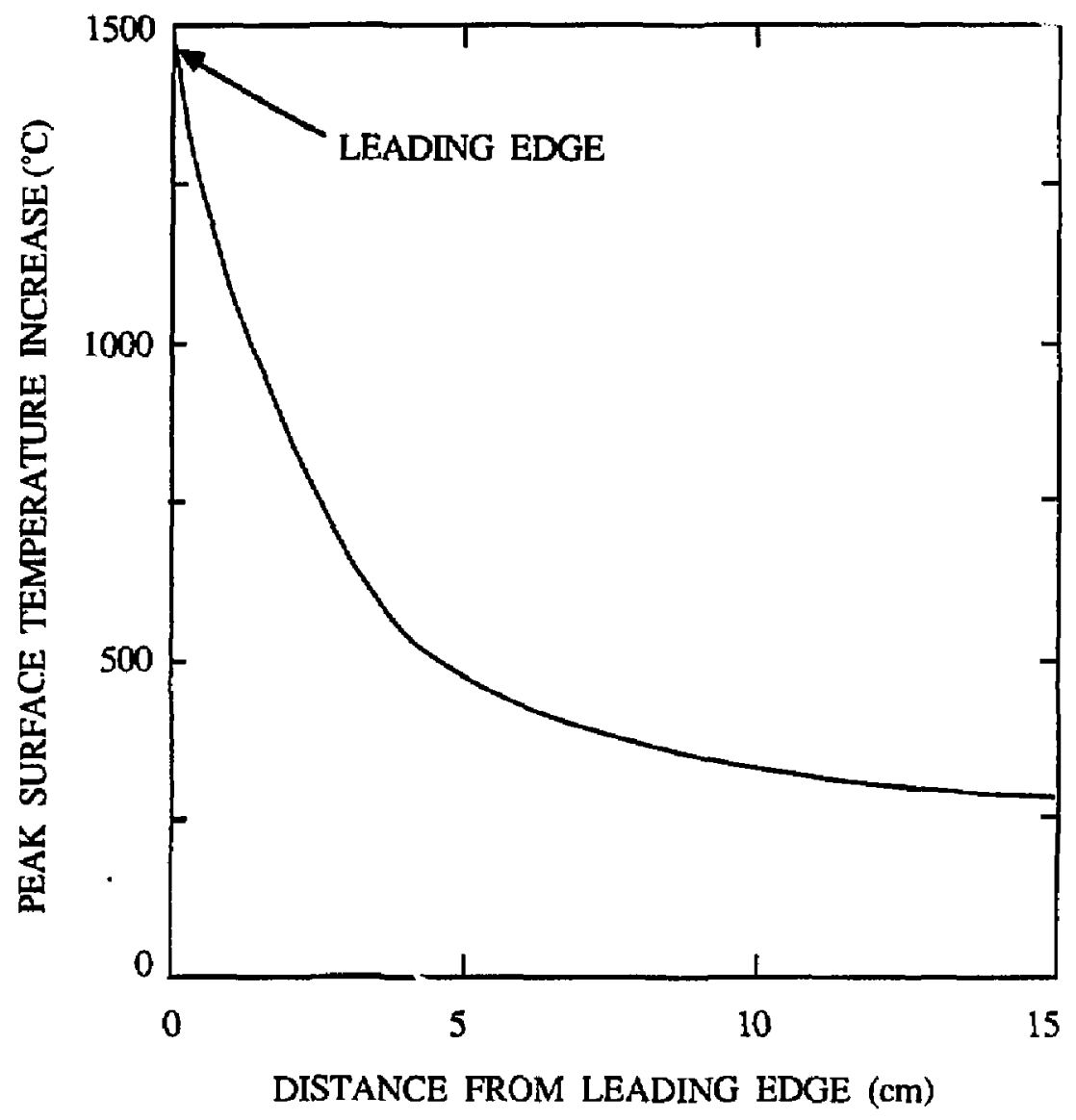

Figure 11 


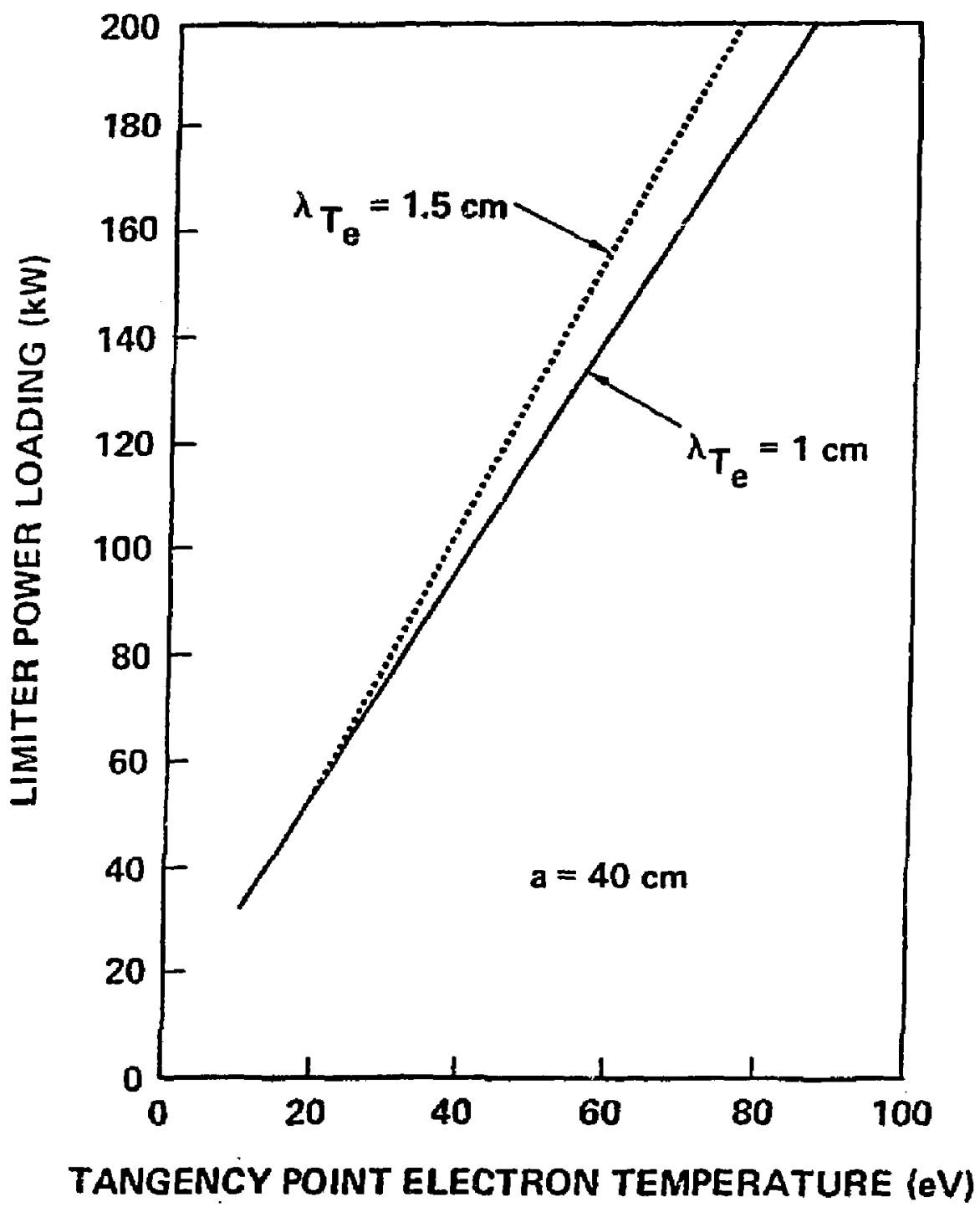

Figure 12 


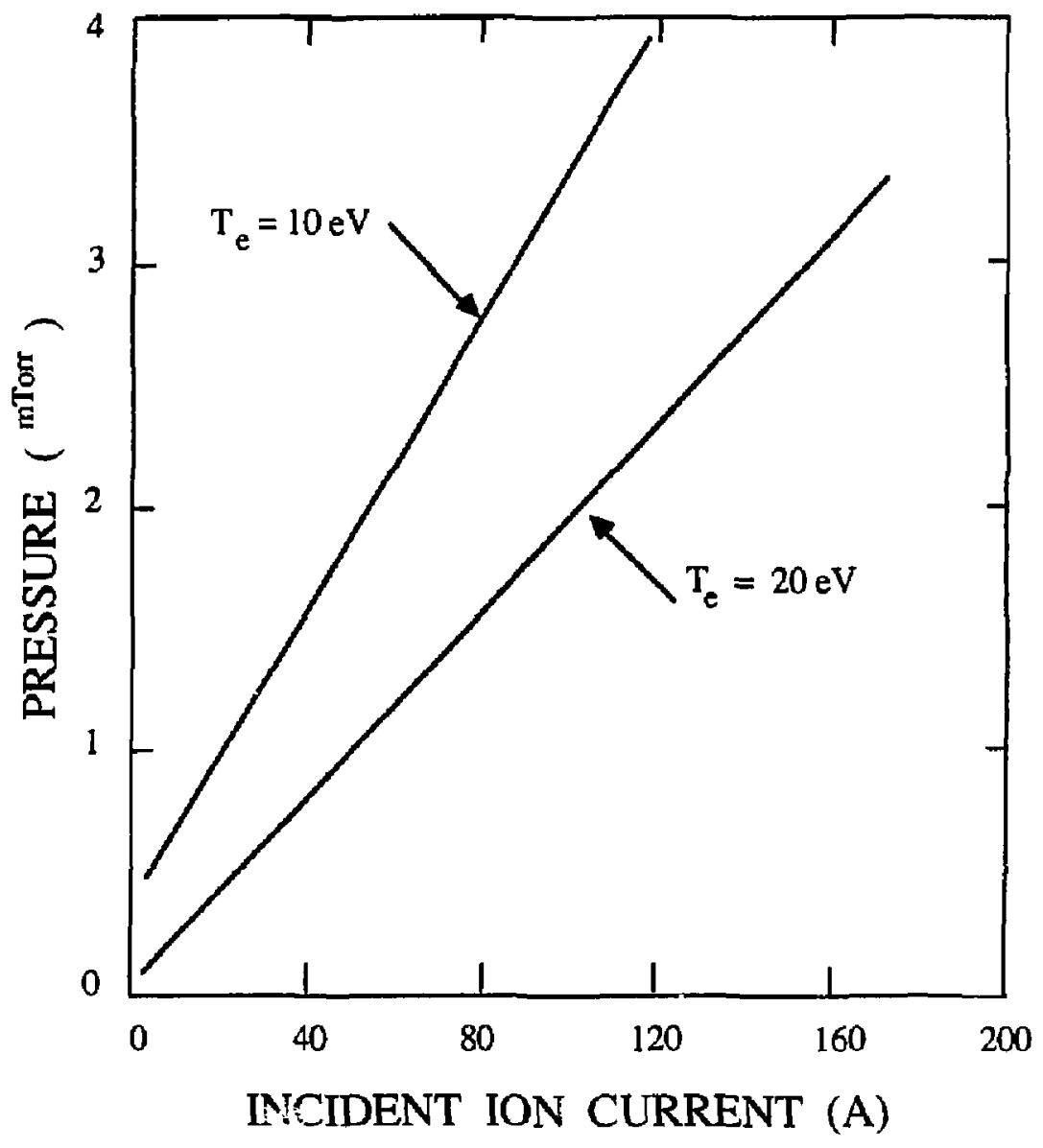

Figure 13 


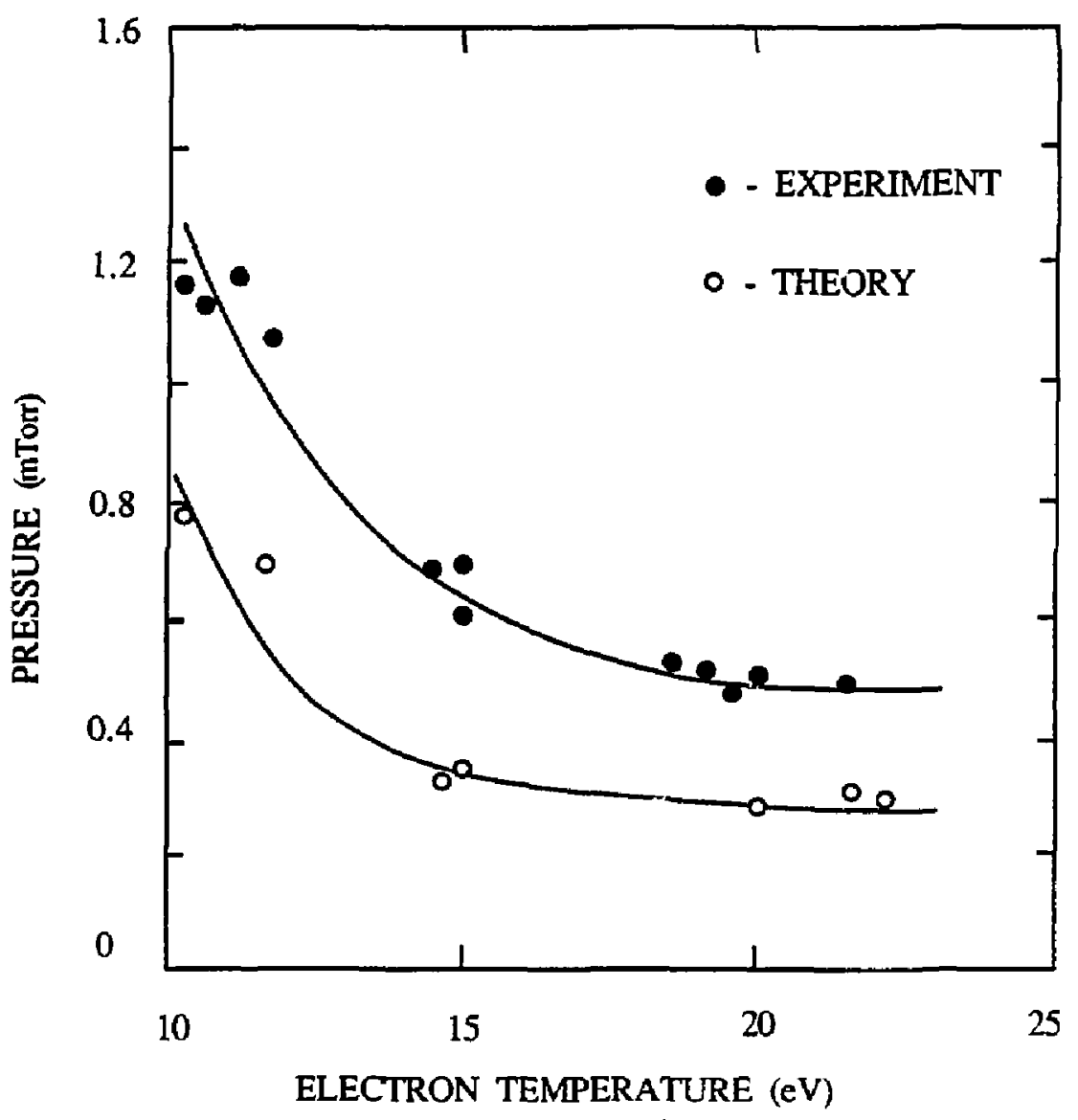

Figure 14 